Tingkat Kebugaran Jasmani Cabang Olahraga Renang pada Mahasiswa Program Studi Pendidikan Jasmani Semester 3 Universitas Tunas Pembangunan Surakarta Tahun 2020

Satrio Sakti Rumpoko, Sunjoyo

\title{
Tingkat Kebugaran Jasmani Cabang Olahraga Renang pada Mahasiswa Program Studi Pendidikan Jasmani Semester 3 Universitas Tunas Pembangunan Surakarta Tahun 2020
}

\section{Physical Fitness Level of Swimming Sports in Students of Physical Education Semester 3, Universitas Tunas Pembangunan Surakarta Year 2020}

\author{
Satrio Sakti Rumpoko ${ }^{a}$, Sunjoyo ${ }^{b}$ \\ a Pendidikan Jasmani, Universitas Tunas Pembangunan, Surakarta, Indonesia \\ ${ }^{b}$ Pendidikan Jasmani, Universitas Tunas Pembangunan, Surakarta, Indonesia \\ email: ${ }^{a}$ saktirumpoko1@gmail.com, ${ }^{b}$ sunjoyo57@gmail.com
}

\begin{tabular}{l} 
I N F O AR TIKEL \\
\hline Sejarah artikel: \\
Menerima 10 \\
Januari \\
$2021 \quad$ Revisi 21 Januari \\
2021 \\
Diterima 31 \\
Online 1 Februari \\
2021 \\
Kata kunci: \\
Tingkat Kebugaran \\
Jasmani, Renang, \\
Mahasiswa \\
pendidikan Jasmani \\
\\
Keywords: \\
Level of Physical \\
Fitness, Swimming, \\
Physical education \\
students
\end{tabular}

\begin{abstract}
ABSTRAK
Penelitian ini bertujuan untuk mengetahui tingkat kesegaran jasmani cabang olahraga renang mahasiswa program studi pendidikan jasmani semester 3 universitas tunas pembangunan surakarta tahun 2020. Subyek dari penelitian ini adalah mahasiswa semester 3 Penjaskes berjumlah 89 orang. Metode Penelitian ini menggunakan metode deskriptif kuantitatif. Teknik pengumpulan data menggunakan tes, Instrumen yang digunakan dalam penelitian ini berupa tes water polo intermittent shuttle test (WIST). Teknik analisis data menggunakan rumus presentase. Hasil penelitian menunjukan dari 58 mahasiswa terdapat 2 mahasiswa $(3,4 \%)$ tergolong kategori baik sekali, 7 mahasiswa (12\%) tergolong kategori baik, 34 mahasiswa (58,6\%) tergolong kategori sedang, 12 mahasiswa (20,8\%) tergolong kategori sedang dan mahasiswa (5,2\%) tergolong kurang. Penjaskes semester 3 setelah dianalisis menggunakan rumus presentase terdapat Kesimpulan adalah tingkat kesegaran jasmani cabang olahraga renang mahasiswa Program Studi Pendidikan Jasmani semester 3 Universitas Tunas Pembangunan surakarta ratarata masuk kedalam kategori sedang yaitu 34 mahasiswa atau 58,6\% dari sample.
\end{abstract}

Kata Kunci : Tingkat Kebugaran Jasmani, Renang, Mahasiswa pendidikan Jasmani

\section{ABSTRACT}

This study aims to find out the level of physical freshness of swimming sports students of physical education study program semester 3 of tunas pembangunan university surakarta in 2020. The subject of this study was 89 penjaskes 3 rd semester students. This research method uses descriptive quantitative method. Data collection techniques using tests, instruments used in this research in the form of water polo intermittent shuttle test (WIST). Data analysis techniques using percentage formulas. The results showed that out of 58 students there were 2 students (3.4\%) very good category, 7 students (12\%) classified as a good category, 34 students $(58.6 \%)$ classified as medium category, 12 students $(20.8 \%)$ moderate and student categories (5.2\%) classified as lacking. Penjaskes semester 3 after analyzed using the percentage formula there Conclusion is the level of physical freshness of swimming sports students Physical Education Study Program semester 3 Tunas Pembangunan University surakarta on average fall into the medium category of 34 students or $58.6 \%$ of the sample.

Keywords: Level of Physical Fitness, Swimming, Physical education students 
Tingkat Kebugaran Jasmani Cabang Olahraga Renang pada Mahasiswa Program Studi Pendidikan Jasmani Semester 3 Universitas Tunas Pembangunan Surakarta Tahun 2020

Satrio Sakti Rumpoko, Sunjoyo

\section{Pendahuluan}

Peningkatan kualitas sumber daya manusia merupakan syarat mutlak untuk mencapai tujuan pembangunan. Tujuan pendidikan adalah seperangkat hasil pendidikan yang dicapai oleh peserta didik setelah diselenggarakannya kegiatan pendidikan. Seluruh kegiatan pendidikan yakni bimbingan dan latihan diarahkan untuk mencapai tujuan pendidikan. Dalam konteks ini, tujuan pendidikan merupakan komponen sistem pendidikan yang menempati kedudukan dan fungsi sentral (Hamalik, 2003:3).

Salah satu faktor penentu dalam tercapainya keinginan untuk mengangkat prestasi olahraga adalah kesegaran jasmani. Dengan tingkat kesegaran jasmani yang baik maka seorang mahasiswa akan memiliki kesanggupan untuk menjalankan tugas atau beban kerja yang diberikan kepadanya, kesegaran yang baik sangat membantu dalam produktivitas dirinya sebagai pelajar sehingga akan belajar dengan giat dan rajin, tangkas menyelesaikan berbagai tugas dan tidak mudah menyerah, sebaliknya bagi yang tingkat kesegaran jasmaninya rendah cenderung akan mudah sakit. Hal ini akan berakibat kepada yang bersangkutan tidak akan sanggup menjalankan beban tugas yang diberikan.

Berdasarkan pengamatan di Program Studi Pendidikan Jasmani, tingkat kesegaran jasmani mahasiswa sangat beragam. Masih banyak mahasiswa yang kurang energik dalam kegiatan perkuliahan. Hal inilah yang menjadi landasan peneliti untuk melihat kesegaran jasmani mahasiswa prodi Pendidikan Jasmani FKIP Universitas Tunas Pembangunan Surakarta. 
Tingkat Kebugaran Jasmani Cabang Olahraga Renang pada Mahasiswa Program Studi Pendidikan Jasmani Semester 3 Universitas Tunas Pembangunan Surakarta Tahun 2020

Satrio Sakti Rumpoko, Sunjoyo

Derajat kesegaran jasmani dapat ditingkatkan melalui keterampilan gerak dasar dan kesehatan melalui pengenalan penggunaan sikap positif dan pengamatan sikap mental yang diimplementasikan dalam berbagai aktivitas agar dapat mencapai pertumbuhan jasmani khususnya tinggi badan dan berat yangideal, secara harmonis dan perkembangan jasmani.

Mutohir (2007:117) menyatakan kesegaran jasmani adalah "kemampuan seseorang yang melakukan tugas-tugas sehari-hari tanpa harus mengalami kelelahan yang berarti”. Menurut Hairy (2007:1.16) kesegaran jasmani tergantung kepada dua komponen dasar, yaitu kebugaran organik (organic fitness) dan kebugaran organik (dynamic fitness). Dua komponen itu sangat penting didalam kebugaran jasmani secara keseluruhan dan interaksi keduanya itu yang menentukan tingkat kebugaran jasmani yang dimiliki.

Kesegaran jasmani, dimaksudnya sifat-sifat khusus yang dimiliki berdasarkan garis keturunan, yang diwarisi oleh kedua orang tua atau bahkan generasi sebelumnya dan dipengaruhi oleh umur dan mungkin oleh keadaan sakit atau kecelakaan termasuk akibat perang. Jika berbicara tentang ukuran tubuh, perkembangannya serta ciri-ciri fisik lainnya, misalnya seseorang berasal dari keturunan sebaliknya. Keadaan yang berhubungan dengan organisme sebenarnya bersifat statis dan sulit atau bahkan tidak mungkin untuk diubah. Tingkat kebugaran organik menentukan potensi kebugaran jasmani secara keseluruhan.

Menurut Luthan (2002:1) kesegaran jasmani mempunyai dua aspek atau komponen yaitu Kekuatan otot, Daya tahan otot, Daya tahan aerobic, Fleksibilitas. Kesegaran yang berkaitan dengan performa: Koordinasi, Agilitas, Kecepatan gerak, Power, Keseimbangan. 
Tingkat Kebugaran Jasmani Cabang Olahraga Renang pada Mahasiswa Program Studi Pendidikan Jasmani Semester 3 Universitas Tunas Pembangunan Surakarta Tahun 2020

Satrio Sakti Rumpoko, Sunjoyo

\section{Metode}

\section{a) Populasi dan Sample}

Dalam penelitian ini, peneliti menggunakan teknik purposive random sampling. Purposive random sampling menurut Sugiyono adalah teknik penentuan sampel dengan pertimbangan tertentu (Sugiyono, 2012 : 68). Kriteria yang digunakan dalam penelitian ini yaitu laki-laki dan perempuan yang mengambil mata kuliah Renang. Sample yang diambil dari penelitian berjumlah 58 mahasiswa, 12 mahasiswa putri dan 46 mahasiswa putra.

\section{b) Instrumen Penelitian}

Instrumen penelitian adalah suatu alat yang digunakan mengukur fenomena alam maupun sosial yang diamati (Sugiyono, 2011:102). Teknik atau caracara yang dapat digunakan oleh peneliti untuk mengumpulkan data. Teknik menunjuk suatu kata yang abstrak dan tidak diwujudkan dalam benda, tetapi hanya dapat dilihat penggunaannya memalui:angket, wawancara pengamatan, ujian (tes), dokumentasi dan lainnya. Peneliti dapat menggunakan salah satu atau gabungan tergantung dari masalah yang dihadapi (Riduwan, 2009:69). Adapun teknik pengumpulan data dalam penelitian ini adalah dengan tes, adapun tes yang digunakan adalah Water Polo Intermittent Shuttle Test (WIST) (Mujika et al., 2006).

Nasution dalam Sugiyono (2011:334), menyatakan bahwa "Melakukan analisis adalah pekerjaan yang sulit, memerlukan kerja keras. Analisis memerlukan daya kreatif serta kemampuan intelektual yang tinggi. Tidak ada cara tertentu yang dapat diikuti untuk mengadakan analisis, sehingga setiap penelitian harus mencari sendiri metode yang dirasakan cocok dengan sifat 
Tingkat Kebugaran Jasmani Cabang Olahraga Renang pada Mahasiswa Program Studi Pendidikan Jasmani Semester 3 Universitas Tunas Pembangunan Surakarta Tahun 2020

Satrio Sakti Rumpoko, Sunjoyo

penelitiannya". Analisis data yang digunakan yaitu dengan rumus Presentase.

$$
\mathrm{P}=\frac{F}{N} \times 100 \%
$$

Keterangan:

$\mathrm{P}=$ Persentase yang dicari

$\mathrm{F}=$ Frekuensi (Jumlah Pilihan Angket)

\section{c) Deskripsi Data Hasil Penelitian}

\section{1) Hasil Tes Mahasiswa Putri}

Berdasarkan hasil pengukuran Water Polo Intermitten Shutle Test (WIST) pada mahasiswa putri diperoleh skor maksimum 8,7 tergolong kategori baik dan skor minimum 4,1 tergolong kategori kurang. Selanjutnya hasil analisis data Water Polo Intermitten Shutle Test (WIST) mahasiswa putri Prodi Pendidikan Jasmani FKIP Universitas Tunas Pembangunan Surakarta dapat diperoleh data distribusi frekuensi sebagai berikut :

Tabel. 1 Distribusi Frekuensi Hasil Tes Mahasiswa Putri

\begin{tabular}{|c|c|c|c|c|}
\hline \multirow{2}{*}{ No } & \multirow{2}{*}{$\begin{array}{c}\text { Kelas } \\
\text { Interval }\end{array}$} & $\begin{array}{c}|c| \\
\text { Absolut } \\
(\mathrm{Fa})\end{array}$ & $\begin{array}{c}\text { Relatif } \\
(\%)\end{array}$ & \multirow{2}{*}{ Kategori } \\
\cline { 3 - 4 } & $10 / 2-12 / 7$ & - & - & Baik Sekali \\
\hline 2 & $8 / 7-10 / 1$ & 3 & 25 & Baik \\
\hline 3 & $7 / 3-8 / 6$ & 6 & 50 & Sedang \\
\hline 4 & $5 / 8-7 / 2$ & 2 & 16,7 & Kurang \\
\hline 5 & $4 / 5-5 / 7$ & 1 & 8,3 & Kurang Sekali \\
\hline
\end{tabular}


Tingkat Kebugaran Jasmani Cabang Olahraga Renang pada Mahasiswa Program Studi Pendidikan Jasmani Semester 3 Universitas Tunas Pembangunan Surakarta Tahun 2020

Satrio Sakti Rumpoko, Sunjoyo

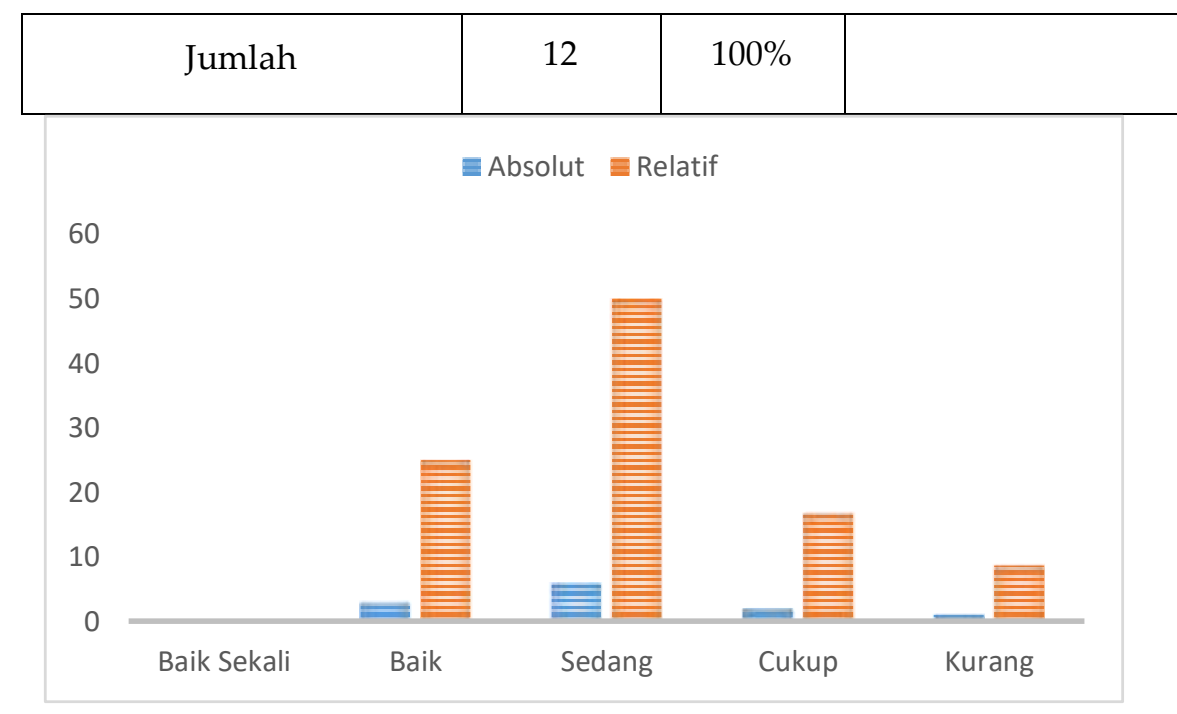

Histogram. 1 Hasil Tes Mahasiswa Putri

Berdasarkan histogram diatas data hasil tes mahasiswa putri sejumlah 12 mahasiswa, 3 mahasiswa (25\%) tergolong kategori baik, 6 mahasiswa (50\%) tergolong kategori sedang, 2 mahasiswa $(16,7 \%)$ tergolong kategori sedang dan 1 mahasiswa (8,3\%) tergolong kurang. Berdasarkan hasil kajian di atas dapat dikemukakan bahwa rata-rata skor tes WIST adalah 7,1 berada dalam kategori sedang.

\section{2) Hasil Tes Mahasiswa Putra}

Berdasarkan hasil pengukuran Water Polo Intermitten Shutle Test (WIST) pada mahasiswa putra yang berjumlah 46 mahasiswa diperoleh skor maksimum 11,5 tergolong kategori baik sekali dan skor minimum 5,1 tergolong kategori kurang. Selanjutnya hasil analisis data Water Polo Intermitten Shutle Test (WIST) mahasiswa putra Prodi Pendidikan Jasmani FKIP Universitas Tunas Pembangunan Surakarta dapat diperoleh data distribusi frekuensi sebagai berikut : 
Tingkat Kebugaran Jasmani Cabang Olahraga Renang pada Mahasiswa Program Studi Pendidikan Jasmani Semester 3 Universitas Tunas Pembangunan Surakarta Tahun 2020

Satrio Sakti Rumpoko, Sunjoyo

Tabel. 2 Distribusi Frekuensi Hasil Tes Mahasiswa Putra

\begin{tabular}{|c|c|c|c|c|}
\hline \multirow{2}{*}{ No } & \multirow{2}{*}{$\begin{array}{c}\text { Kelas } \\
\text { Interval }\end{array}$} & $\begin{array}{c}|c| \\
\text { Absolut } \\
(\text { Fa })\end{array}$ & $\begin{array}{c}\text { Relatif } \\
(\%)\end{array}$ & \multirow{2}{*}{ Kategori } \\
\cline { 3 - 4 } & $11 / 6-13 / 10$ & 2 & 4,3 & Baik Sekali \\
\hline 1 & $10 / 2-11 / 5$ & 4 & 8,7 & Baik \\
\hline 2 & $8 / 6-10 / 1$ & 28 & 61 & Sedang \\
\hline 3 & $7 / 2-8 / 5$ & 10 & 21,7 & Kurang \\
\hline 4 & $5 / 2-7 / 1$ & 2 & 4,3 & Kurang Sekali \\
\hline 5 & & 12 & $100 \%$ & \\
\hline
\end{tabular}

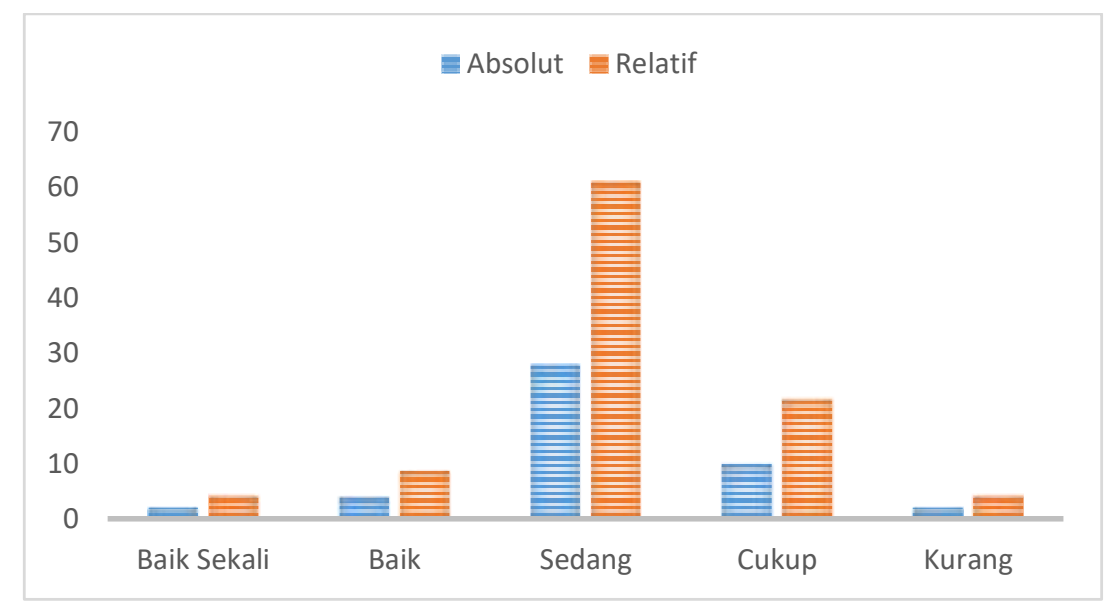

Histogram. 2 Hasil Tes Mahasiswa Putri

Berdasarkan histogram diatas data hasil tes mahasiswa putra sejumlah 46 mahasiswa, 2 mahasiswa (4,3\%) tergolong kategori baik sekali, 4 mahasiswa (8,7\%) tergolong kategori baik, 28 mahasiswa (61\%\%) tergolong kategori sedang, 10 mahasiswa (21,7\%) tergolong 
Tingkat Kebugaran Jasmani Cabang Olahraga Renang pada Mahasiswa Program Studi Pendidikan Jasmani Semester 3 Universitas Tunas Pembangunan Surakarta Tahun 2020

Satrio Sakti Rumpoko, Sunjoyo

kategori sedang dan 2 mahasiswa (4,3\%) tergolong kurang. Berdasarkan hasil kajian di atas dapat dikemukakan bahwa rata-rata skor tes WIST adalah 8,2 berada dalam kategori sedang.

\section{Simpulan}

Berdasarkan hasil penelitian yang telah diuraikan dapat dikemukakan kesimpulan bahwa tingkat kesegaran jasmani cabang olahraga renang mahasiswa prodi Pendidikan Jasmani FKIP Universitas Tunas Pemangunan Surakarta adalah 34 mahasiswa masuk kategori sedang sebesar 58,62\%. Artinya, belum memiliki tingkat kesegaran jasmani yang baik. Apabila semakin baik tingkat kesegaran jasmani mahasiswa, maka semakin baik tingkat penampilan mahasiswa dalam meningkatkan kualitas belajar. Sebaliknya, apabila tingkat kesegaran jasmani kurang, maka mahasiswa tidak dapat menampilkan kualitas belajar yang baik. 
Tingkat Kebugaran Jasmani Cabang Olahraga Renang pada Mahasiswa Program Studi Pendidikan Jasmani Semester 3 Universitas Tunas Pembangunan Surakarta Tahun 2020

Satrio Sakti Rumpoko, Sunjoyo

4. Referensi

Hairy, Junursul. 2007. Dasar-Dasar Kesehatan Olahraga. Jakarta: Depdiknas

Hamalik, Oemar. 2003. Proses Belajar Mengajar. Jakarta: Bumi Aksara. Kementerian Pendidikan Nasional. 2010. Tes Kesegaran Jasmani Indonesia.Jakarta: Kementerian Pendidikan Nasional Pusat Pengembangan KualitasJasmani.

Luthan. 2002. Supervisi Pendidikan Jasmani. Jakarta: Departemen Pendidikan Nasional.

Mujika, I., McFadden, G., Hubbard, M., Royal, K., \& Hahn, A. 2006. The water-polo intermittent shuttle test: a match-fitness test for water-polo players. International Journal of Sports Physiology and Performance, 1(1), 27-39.

Mutohir, T. Cholik. 2007. Gagasan-Gagasan Tentang Pendidikan Jasmani dan Olahraga. Surabaya: Unesa Universty Press

Riduwan. 2009. Rumus dan Data dalam Analisis Statika. Bandung: Alfebeta.

Sugiyono. 2011. Metode Penelitian Kuantitatif Kualitatif dan $R \& D$. Bandung: PT Rineka Cipta. 